\title{
Benign Metastatic Leiomyoma: Unusual Heart Location
}

\author{
Elaouni $\mathrm{S}^{1,2,3 *}$, J ebli $\mathrm{S}^{1,2}$, Sassi $\mathrm{S}^{1,2}$, Bernoussi $\mathrm{Z}^{1,2}$, \\ J ahid $A^{1,2}$, Zouidia $F^{1,2}$ and Znati $K^{1,2}$ \\ ${ }^{1}$ Department of Pathology, Ibn Sina Hospital, University \\ in Rabat, Morocco \\ ${ }^{2}$ University Mohamed V Rabat, Faculty of Medicine and \\ Pharmacy, Morocco \\ ${ }^{3}$ Department of Pathology, Ibn Sina Hospital, University \\ Mohamed V Rabat, Morocco \\ *Corresponding author: Elaouni S, Department of \\ Pathology, Ibn Sina Hospital, University Mohamed V \\ Rabat, Morocco
}

Received: April 06, 2021; Accepted: April 26, 2021; Published: May 03, 2021

\begin{abstract}
Cardiac smooth muscle tumors are rare; three different clinical settings for these tumors have been reported, including benign metastasizing leiomyoma from the uterus, primary cardiac leiomyoma and leiomyosarcoma, and intravenous cardiac extension of pelvic leiomyoma, which is the most common. We present a case of a 56-year-old woman with a benign metastasizing leiomyoma to the heart without associated pulmonary localization 15 years after endoscopic vaginal myomectomy of polymyomatous uterus. Immunohistochemical stains for $\mathrm{H}$-Caldesmon, Desmin, and estrogen, progesterone receptors were positive, indicating a smooth muscle tumor of uterine origin. To our knowledge, this is only the fifth reported case of benign metastasizing leiomyoma to the heart with histological proof and the first case of earlier onset cardiac metastasis without pulmonary metastasis localization. It illustrates that benign metastasizing leiomyoma should be included in the differential diagnosis of cardiac tumors in patients with a history of surgery uterine leiomyoma perfectly benign.
\end{abstract}

Keywords: Heart; Benign metastasizing leiomyoma; Uterine surgery

\section{Introduction}

Primary cardiac tumors are rare, and most cardiac tumors are secondary to metastatic disease [1]. Smooth muscle tumors of the heart are extremely rare. Three different clinical settings for cardiac smooth muscle tumors have been reported: intravenous cardiac extension of pelvic leiomyomas [2] benign metastasizing leiomyomas from the uterus $[1,3,4]$ and primary cardiac leiomyomas and leiomyosarcomas [5]. Here we report a rare entity of metastasizing leiomyoma to the heart with review of the literature.

\section{Case Presentation}

A 56-year-old woman presented at a provincial hospital with dyspnea and shortness of breath. On imaging, she was found to have a right atrial mass initially thought to be a thrombus. She was subsequently referred to university hospital center (CHU Ibn Sina, Rabat) for further workup and management. Cardiac Magnetic Resonance Imaging (MRI) showed a monolobed, pedunculated, mobile, well-circumscribed mass attached to the intra-atrial septum. The resected tumor was sent to us for histological confirmation. Pulmonary radiological exploration did not find a suspicious mass.

Additional history was pursued as part of the pathologic workup, and it was determined that the patient had undergone a uterine surgery endoscopic vaginal of polymyomatous uterine 15 years earlier at the age of 41 years. The uterine mass operated on was a leiomyoma with no malignant features; no necrosis, atypia, or increased mitotic activity was seen. The patient lost to follow up until she consulted for her cardiac symptomatology resulting in a discovery of mass in the right atrium.

The $8 \mathrm{~cm} \times 5 \mathrm{~cm} \times 3 \mathrm{~cm}$ resected cardiac tumor was solid, graywhite, and homogeneous fasciculate with no hemorrhage or necrosis (Figure 1). Microscopically, the tumor was composed of bundles of bland spindle cells with "cigar-shaped nuclei", no nuclear atypia or necrosis, and only rare mitoses (less than 1/10 high-power

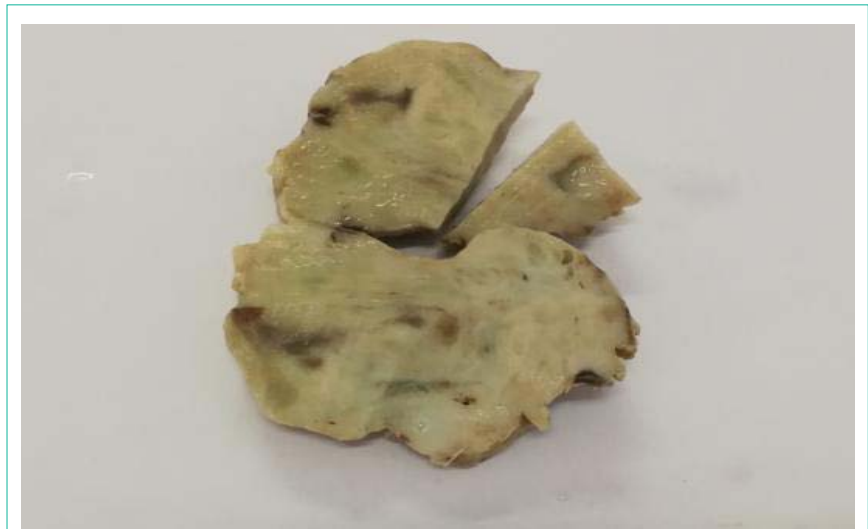

Figure 1: The 4-cm resected cardiac tumor was solid, gray-white, and homogeneous with no hemorrhage or necrosis.

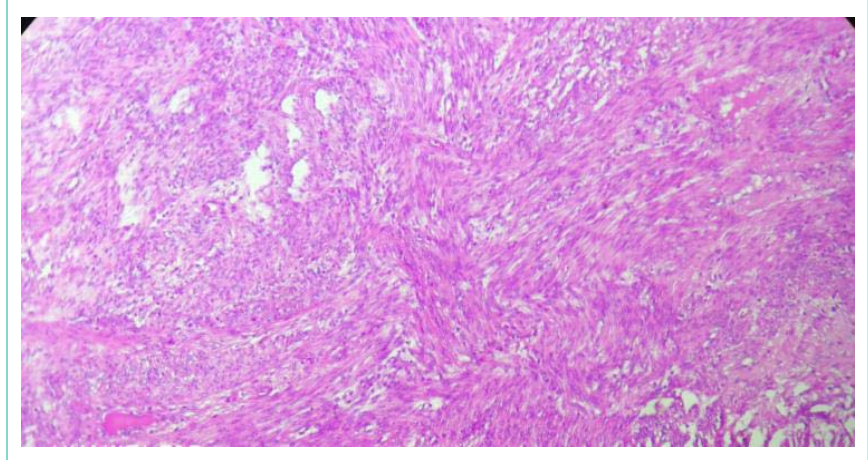

Figure 2: The tumor is composed of bundles of bland spindle cells with "cigar-shaped nuclei", no nuclear atypia or necrosis, and only rare mitoses (less than 1/10 high power fields: hematoxylin and eosin stain).

fields) (Figure 2). Immunohistochemically, the spindle tumor cells expressed H-Caldesmon (Figure 3) and Desmin (Figure 4) and were negative for S100 (Figure 5) Protein. MIB-1 immunohistochemical 


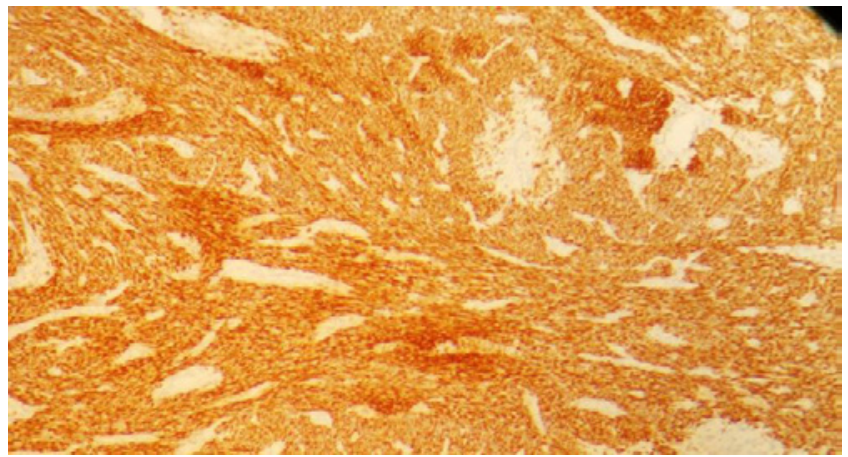

Figure 3: The tumor cells were diffusely strongly positive for $\mathrm{H}$-caldesmone.

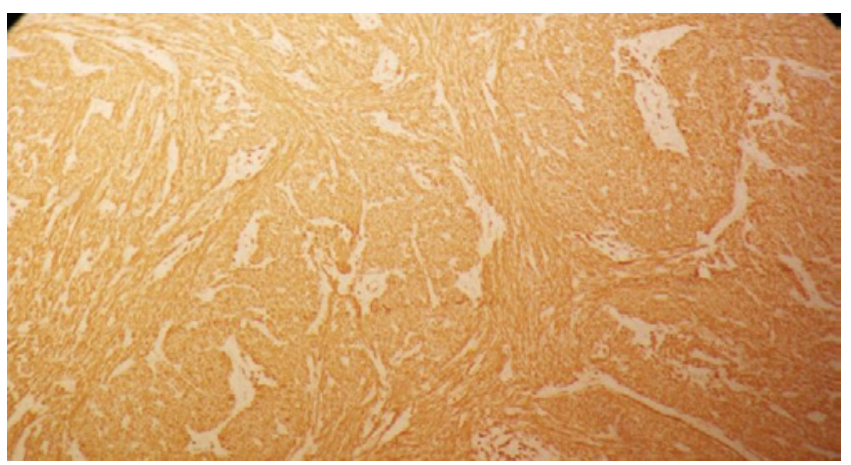

Figure 4: The tumor cells were diffusely strongly positive for Desmine.

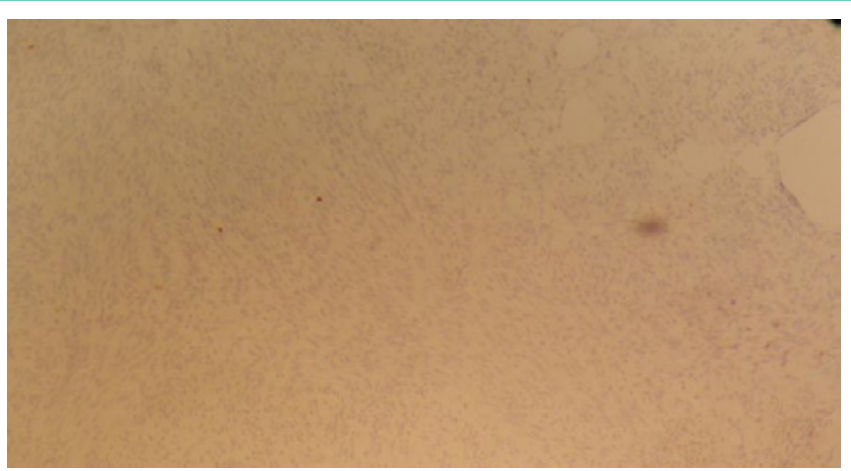

Figure 5: The tumor cells were negative for S100 Protein.

staining showed low proliferative activity, with less than $1 \%$ MIB1-positive cells. The tumor cells were strongly positive for Estrogen Receptors (ER) and for Progesterone Receptors (PR) (Figure 6 and 7), supportive of uterine origin. The patient is alive and well 16 months after resection of the cardiac tumor, with no evidence of further metastasis.

\section{Discussion}

Benign metastatic leiomyoma is a rare pathology and its terminology is even debated, because the occurrence of metastasis to contradict their histologically benign character [6].

Benign metastasizing leiomyoma is an extrauterine smooth muscle tumor that occurs in patients with a current or prior history of uterine leiomyoma [7-9]. It has been reported in multiple

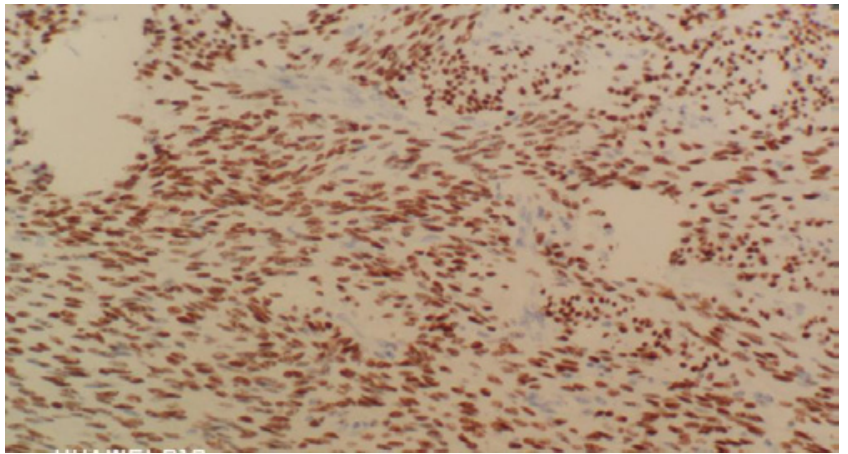

Figure 6: The tumor cells were diffusely strongly positive for Estrogene receptor.

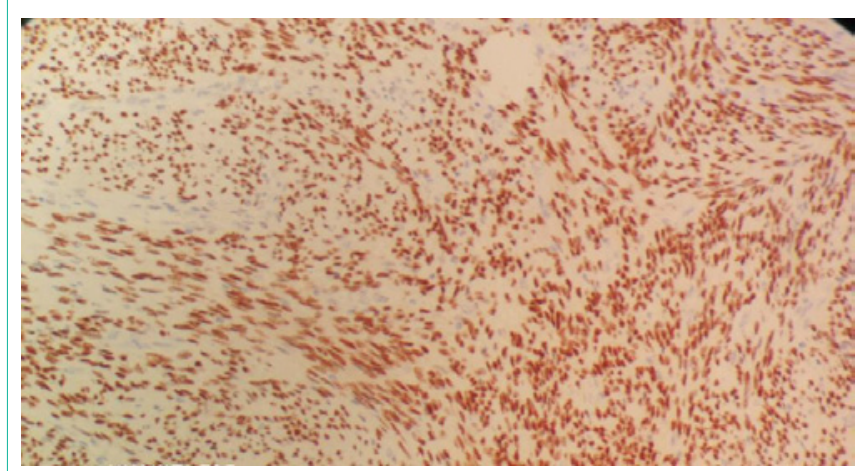

Figure 7: The tumor cells were diffusely strongly positive for Progesterone receptor.

locations, with the lung being the most common metastatic site [79], but metastases have also been reported in the skull base [10], spine [11], rib [11], vertebrae [11], lymph nodes [12], and pelvis [13]. Of smooth muscle tumors found in the heart, three types of tumors have been reported: primary cardiac smooth muscle tumors (leiomyoma or leiomyosarcoma) [5], intravenous smooth muscle tumors with intracardiac extension [2,5], and benign metastasizing leiomyoma $[1,3,4]$. Although all three entities are rare, intravenous extension into the heart is the most common, with more than 100 reported cases since the early 1900s [2], and the least reported type is benign metastasizing leiomyoma It is not excluded, without being proven, that their physiopathology is common [14,15]. Furthermore, it is necessary to confirm the diagnosis by histological examination in order to rule out the differential diagnosis of leiomyosarcoma, which may have the same clinical characteristics as benign metastatic leiomyoma [16-17]. To the best of our knowledge, there are only four prior case reports of benign metastasizing leiomyoma to the heart (Table 1) $[1,3,4]$. Galvin et al. reported a case of a 41-yearold woman with an isolated right ventricular metastasis who had undergone a hysterectomy 3 months prior [1]. A benign leiomyoma was found in the resected uterus, which had been present 7 years prior at cesarean section. The cardiac tumor, a pedunculated mass attached to the interventricular septum, was resected and diagnosed as a benign leiomyoma. No intravenous leiomyoma was found. The cardiac tumor was ER- and PR-positive. Takemura et al. described a case of a 44-year-old woman who presented with dyspnea and a cardiac murmur after having had a hysterectomy for a leiomyoma 
Table 1: Case reports of benign metastasizing leiomyoma to the heart.

\begin{tabular}{|c|c|c|c|c|c|}
\hline Case & Age & Lung metastasis & Interval to metastasis & Location in Heart & $\begin{array}{l}\text { ER and PR } \\
\text { status }\end{array}$ \\
\hline $\begin{array}{c}\text { Case } 1 \\
\text { (Glavin et al.) }\end{array}$ & 41 & None & $\begin{array}{c}\text { Cardiac metastasis found } 3 \text { months after elective cesarean } \\
\text { section and hysterectomy }\end{array}$ & $\begin{array}{l}\text { Attached to the right anterio } \\
\text { interventricular septum }\end{array}$ & Both positive \\
\hline $\begin{array}{c}\text { Case } 2 \\
\text { (Takemura et al.) }\end{array}$ & 45 & $\begin{array}{l}\text { Multiple, synchrone with } \\
\text { cardiac metastasis }\end{array}$ & $\begin{array}{l}\text { Synchronous cardiac and pulmonary metastases found } 4 \\
\text { years after hysterectomy }\end{array}$ & $\begin{array}{l}\text { Attached to antrior papillary } \\
\text { muscle of right ventricule }\end{array}$ & Not done \\
\hline $\begin{array}{c}\text { Case } 3 \\
\text { (Thukkani et al.) }\end{array}$ & 36 & $\begin{array}{l}\text { Multiple,10 years prior to } \\
\text { cardiac metastasis }\end{array}$ & $\begin{array}{l}\text { Cardiac metastasis } 10 \text { years after hysterectomy; Lung } \\
\text { metastasis found after hysterectomy prior to cardiac } \\
\text { metastasis (exact time interval not reported) }\end{array}$ & Tricuspid valve & Not done \\
\hline $\begin{array}{c}\text { Case } 4 \\
\text { (Consamus et al.) }\end{array}$ & 55 & $\begin{array}{l}\text { Multiple, } 16 \text { years prior to } \\
\text { cardiac metastasis }\end{array}$ & $\begin{array}{c}\text { Lung metastasis } 1 \text { year after hysterectomy; Cardiac } \\
\text { metastasis } 16 \text { years after hysterectomy }\end{array}$ & Right atruim & $\begin{array}{l}\text { ER positive } \\
\text { PR positive }\end{array}$ \\
\hline Present Case & 56 & Absent & $\begin{array}{c}\text { Cardiac metastasis } 15 \text { year after myomectomy endoscopic } \\
\text { vaginal }\end{array}$ & Right atruim & $\begin{array}{l}\text { ER positive } \\
\text { PR positive }\end{array}$ \\
\hline
\end{tabular}

ER: Estrogen Receptor; PR: Progesterone Receptor.

4 years prior [3]. A pedunculated mass attached to the anterior papillary muscle of the right ventricle was resected and diagnosed as a benign leiomyoma. Several synchronous, nearly identical-appearing pulmonary nodules were found at surgery. These were biopsied and diagnosed as leiomyomata. The tumors were consistent with benign metastasizing leiomyomata both clinically and pathologically. There was no mention of immunohistochemical evaluation for hormone receptors. Thukkani et al reported a case of a 36-year-old woman who had undergone hysterectomy and left salpingo-oophorectomy for a uterine leiomyoma [3]. Postoperatively, she was found to have metastasis in her lungs and residual tumor within the pelvis. The patient underwent resection of the pelvic mass, requiring a right salpingo-oophorectomy and left nephrectomy. She was then treated with a gonadotropin-releasing hormone agonist. Ten years after the hysterectomy, she developed bilateral pedal edema and underwent a cardiac workup. She was found to have multiple pedunculated lesions attached to the tricuspid valve that, histologically, were leiomyomata. No mention of immunohistochemical stains for hormone receptors was made.

In cases of apparent benign metastasizing leiomyoma, the possibility of under-interpretation of leiomyosarcoma should be considered. It is widely accepted that mitotic rate, cytologic atypia, and presence of coagulative necrosis are the most important predictors of malignant potential in uterine smooth muscle tumors. When metastasis occurs with malignant lesions, the clinical course is generally more aggressive compared to the indolent course seen in benign metastasizing leiomyomata [15]. Our case illustrates the indolent course these tumors can take, even with metachronous pulmonary and cardiac metastases.

\section{Conclusion}

This case illustrates that smooth muscle tumors of the uterus may rarely metastasize to the heart, particularly in the situation no associated with lung metastasis. Including our case, the only one of four cases having pulmonary exploration. Since cardiac metastasis may be long-delayed, prolonged clinical follow-up is recommended.

\section{References}

1. Galvin SD, Wademan B, Chu J, Bunton RW. Benign metastasizing leiomyoma: a rare metastatic lesion in the right ventricle. Ann Thorac Surg. 2010; 89: 279-281.

2. Kocica MJ, Vranes MR, Kostic D, Kovacevic-Kostic N, Lackovic V, BozicMihajlovic $\mathrm{V}$, et al. Intravenous leiomyomatosis with extension to the heart: rare or underestimated? J Thorac Cardiovasc Surg. 2005; 130: 1724-1726.
3. Takemura G, Takatsu Y, Kaitani K, Ono M, Ando F, Tanada S, et al. Metastasizing uterine leiomyoma. A case with cardiac and pulmonary metastasis. Pathol Res Pract. 1996; 192: 622-629. Discussion 630-633.

4. Thukkani N, Ravichandran PS, Das A, Slater MS. Leiomyomatosis metastatic to the tricuspid valve complicated by pelvic hemorrhage. Ann Thorac Surg. 2005; 79: 707-709.

5. Qin C, Chen L, Xiao YB, Chen BC. Giant primary leiomyoma of the right ventricle. J Card Surg. 2010; 25: 169-171.

6. Zhang G, Yu X, Lang J. Intravenous leiomyomatosis with inferior vena cava or intracardiac extension and concurrent bilateral multiple pulmonary nodules. Medicine (Baltimore). 2016: 95: e4722.

7. Ahmad SZ, Anupama R, Vijaykumar DK. Benign metastasizing leiomyoma case report and review of literature. Eur J Obstet Gynecol Reprod Biol. 2011; 159: $240-241$.

8. Awonuga AO, Shavell VI, Imudia AN, Rotas M, Diamond MP, Puscheck EE. Pathogenesis of benign metastasizing leiomyoma: a review. Obstet Gynecol Surv. 2010; 65: 189-195.

9. Goto T, Maeshima A, Akanabe K, Hamaguchi R, Wakaki M, Oyamada Y, et al. Benign metastasizing leiomyoma of the lung. Ann Thorac Cardiovasc Surg. 2012; 18: 121-124.

10. Alessi G, Lemmerling M, Vereecken L, De Waele L. Benign metastasizing leiomyoma to skull base and spine: a report of two cases. Clin Neurol Neurosurg. 2003; 105: 170-174.

11. Kang MW, Kang SK, Yu JH, Lim SP, Suh KS, Ahn JS, et al. Benign metastasizing leiomyoma: metastasis to rib and vertebra. Ann Thorac Surg. 2011; 91: 924-926

12. Yoon G, Kim TJ, Sung $\mathrm{CO}$, Choi $\mathrm{CH}$, Lee JW, Lee $\mathrm{JH}$, et al. Benign metastasizing leiomyoma with multiple lymph node metastasis: a case report. Cancer Res Treat. 2011; 43: 131-133.

13. Egberts JH, Schafmayer C, Bauerschlag DO, Janig U, Tepel J. Benign abdominal and pulmonary metastasizing leiomyoma of the uterus. Arch Gynecol Obstet. 2006; 274: 319-322.

14. Jautzke G, Muller-Ruchholtz E, Thalmann U. Immunohistological detection of estrogen and progesterone receptors in multiple and well differentiated leiomyomatous lung tumors in women with uterine leiomyomas (so-called benign metastasizing leiomyomas). A report on 5 cases. Pathol Res Pract. 1996; 192: 215-223.

15. Rivera JA, Christopoulos S, Small D, Trifiro M. Hormonal manipulation of benign metastasizing leiomyomas: report of two cases and review of the literature. J Clin Endocrinol Metab. 2004; 89: 3183-3188.

16. Wang H-C, Wang Y-B, Chen X-H, Cui L-L. Uterine intravenous leiomyomatosis with intracardiac extension and pulmonary benign metastases on FDG PET/ CT: a case report. Korean J Radiol. 2016; 17: 289-294.

17. Mahmoud MS, Desai K, Nezhat FR. Leiomyomas beyond the uterus; benign metastasizing leiomyomatosis with paraaortic metastasizing endometriosis and intravenous leiomyomatosis: a case series and review of the literature. Arch Gynecol Obstet. 2015; 291: 223-230. 